\title{
Optimization of inbound logistics cost in automotive industry
}

\author{
Inaki Maulida Hakim ${ }^{1, *}$, Rolina Oktapiani Zaqiah ${ }^{1}$ and Teuku Yuri M. Zagloel ${ }^{1}$ \\ ${ }^{1}$ Department of Industrial Engineering,Faculty of Engineering, Universitas Indonesia, 16424 Depok, \\ Indonesia
}

\begin{abstract}
The increasing growth of automotive industry in Indonesia has not been matched by the number of local suppliers and makes the automotive industry too dependent on imported raw materials. Along with the needs of import activities, it is also required a greater logistics activities. However, with high logistics costs, the manufacturer must increase efficiency to be able to compete in the global market. This can be accomplished by planning inbound logistics activities that control the movement of materials from suppliers to the manufacture. In this research, an optimization methodology, based on Mixed Integer Nonlinear Programming (MINLP) approach is developed and solved with branch and bound algorithm. The result of this research, which obtained the total cost of optimal inbound logistics include material cost, transportation cost, and administration cost. This model can also be used as a tool for the company in making decisions about the type and the number of container also with the total of the optimal material load in each container, therefore the optimal container space utilization value can be obtained.
\end{abstract}

\section{Introduction}

As the second-largest car manufacturing nation in Southeast Asia and the ASEAN region, the automotive industry in Indonesia has always been attempted to focus on efficient and cost effective operation. Regarding cost contribution, raw material is a major part of the total cost. Meanwhile, automotive industry in Indonesia is still primarily dependent on imported raw materials. Such imports are needed as the domestic upstream manufacturing industry in Indonesia is still underdeveloped. As a result, transportation cost is also a significant cost contributor, considering the number of suppliers and the distance from the suppliers. Transportation is a complex domain with many players and many decision levels. Transportation accounts for a major part of the gross national product of most countries. In Indonesia alone, approximately $25 \%$ of the GNP is due to transportation. In order to lower transportation cost, the management of a supply chain encompasses the planning of all activities involved to bring the materials to the manufacture, and includes coordination and collaboration with suppliers which also known as inbound logistics, become an important aspect to be considered by the automotive industry.

\footnotetext{
* Corresponding author: inakimhakim@eng.ui.ac.id
} 
The goal of inbound logistics is to reduce the total cost by having the right materials at the right place and at the right time [1]. Over the years, it has been suggested that the companies should pay more attention to a constant inbound logistics management. It can be argued, that inbound logistics is one of the most crucial field to improve: firstly, inbound logistics is the starting point of the supply process and if something goes wrong at that point, it will affect to all of the following processes [2]. If there are problems in the firm's inbound logistics flow, the worst case is that the assembly line has to stop due to the lack of materials (i.e. parts), which will cost a lot of money. Hence, by considering inbound logistics, companies can save big amounts of money but also the reliability of the production becomes more robust [3]. In terms of cost, the inbound logistics cost is the major cost in the product value which comprises of the material, delivery, administration, and inventory cost. However, the level of the delivery planning efficiency has a great impact on all logistics costs and performance [4]. The inefficient planning may cause low container utilization, high delivery cost, or high inventory of excess stock. On the other hand, the decision making in other functions such as the container size selected, minimum order quantity, and loading agreement made with supplier also bring difficulties to the delivery planning and cause the inevitable cost.

From a systems modeling perspective, the inbound logistics problem is a knapsack problem but there are other optimization models used by previous studies. Regarding to delivery planning, $\mathrm{Wu}$ and Lai determine the optimal container size selection and cargo loading strategy to minimize the total rental cost of container that faced by a forwarding company using Mixed Integer Linear Programming (MILP) [5]. Meanwhile, Cochran, J. and Ramanujam, B succeed to minimize total inbound logistics by selecting the correct packaging type and the correct container for each part number also by using Mixed Integer Linear Programming (MILP) [6]. The cost include origin cost, freight cost, and destination cost. As a result, they also optimize the container space utilization. McDonald, $\mathrm{C}$ also do the same studies as previous which minimize inbound logistics cost [7]. However, he succed to optimize the type and number of container used using Mixed Integer Nonlinear Programming (MINLP). Therefore, the aims of this study is to minimize total inbound logistics cost by develop material delivery planning optimization model to determine the type and the number of container used as well as the total optimal material load in each container, thus the optimal container space utilization value is obtained.

\section{Methodology}

Logistics has become an integral part of the business operations of both manufacturing and service companies. Due to the inherent complexity of decision making in supply chains, there is an increasing need for the application of optimization modeling methodologies. Therefore, the goal of logistics optimization is to allow the company to make complex judgments and accurate decisions regarding all facets of the logistics function such as inbound logistics [8]. This often involves the application of mathematical modeling techniques such linear or nonlinear programming to formulate the optimization logistics problem. Figure 1 show the conceptual framework in this study which will be used as a basis in the development of mathematical model formulation. 


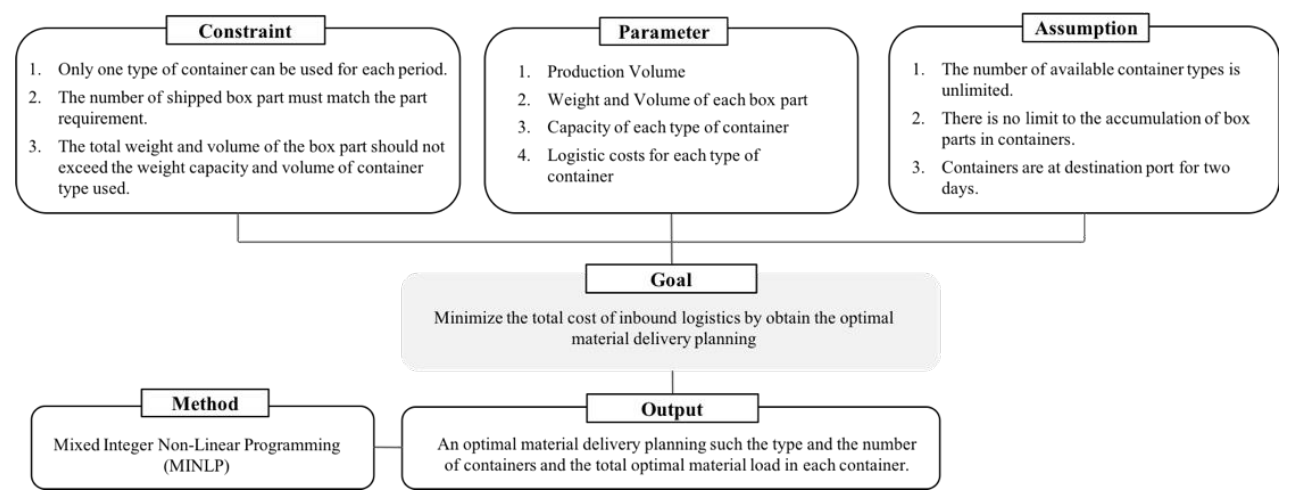

Fig. 1. Conceptual Framework for the Mathematical Model

Index :

$$
\begin{array}{ll}
p & =\text { index of part }(p=1, \ldots, \mathrm{j}) \\
c & =\text { index of container type }(c=1, \ldots, \mathrm{k}) \\
t & =\text { index of period }(c=1, \ldots, \mathrm{m})
\end{array}
$$

Parameters :

$$
\begin{array}{ll}
v \text { prot }_{\mathrm{t}} & =\text { production volume (unit) } \\
v \text { bom }_{\mathrm{p}} & =\text { bill of materials for each part (unit) } \\
f_{\mathrm{pt}} & =\text { total part needed (unit) } \\
w_{\mathrm{p}} & =\text { weight of box part }(\mathrm{kg} / \mathrm{box}) \\
v_{\mathrm{p}} & =\text { volume of box part }\left(\mathrm{m}^{3} / \mathrm{box}\right) \\
c b_{\mathrm{p}} & =\text { material quantities per box }(\text { part } / \mathrm{box}) \\
n_{\mathrm{p}} & =\text { material price }(\$ / \text { box }) \\
w g_{\mathrm{c}} & =\text { weight limits of container }(\mathrm{kg}) \\
v o_{\mathrm{c}} & =\text { volume limits of container }\left(\mathrm{m}^{3}\right) \\
c b_{\mathrm{p}} & =\text { material quantities per box }(\mathrm{part} / \mathrm{box}) \\
s f_{\mathrm{c}} & =\text { cost of sea freight }(\$ / \text { container }) \\
t t_{\mathrm{c}} & =\text { cost of trucking }(\$ / \text { container }) \\
h a_{\mathrm{c}} & =\text { terminal handling cost }(\$ / \text { container }) \\
l o_{\mathrm{c}} & =\text { cost of lift on/lift off }(\$ / \text { container }) \\
c u_{\mathrm{c}} & =\text { cost of customs }(\$ / \text { container }) \\
s t o_{\mathrm{c}} & =\text { cost of storage port }(\$ / \text { container })
\end{array}
$$

Decision variables :

$\begin{array}{ll}Y_{\mathrm{ct}} & =\text { decision for the type of container used } \\ Z_{\mathrm{ct}} & =\text { number of container used } \\ X_{\mathrm{pct}} & =\text { total of box part to be shipped } \\ T P_{\mathrm{pt}} & =\text { number of box part in a container } \\ S M_{\mathrm{pt}} & =\text { number of set part in a container }\end{array}$

Objective function :

$$
\operatorname{Min} Z=\sum_{\mathrm{p}=1}^{\mathrm{j}} \sum_{\mathrm{c}=1}^{\mathrm{k}} \sum_{\mathrm{t}=1}^{\mathrm{m}} X_{\mathrm{pct}} \mathrm{n}_{\mathrm{p}}+\sum_{\mathrm{c}=1}^{\mathrm{k}} \sum_{\mathrm{i}=1}^{\mathrm{m}}\left(\mathrm{sf}_{\mathrm{c}}+\mathrm{tt}_{\mathrm{c}}\right) \mathrm{Z}_{\mathrm{ct}}+\sum_{\mathrm{c}=1}^{\mathrm{k}} \sum_{\mathrm{t}=1}^{\mathrm{m}}\left(\mathrm{ha}_{\mathrm{c}}+\mathrm{lo}_{\mathrm{c}}+\mathrm{cu}_{\mathrm{c}}+\mathrm{sto}_{\mathrm{c}}\right)
$$

Subject to : 


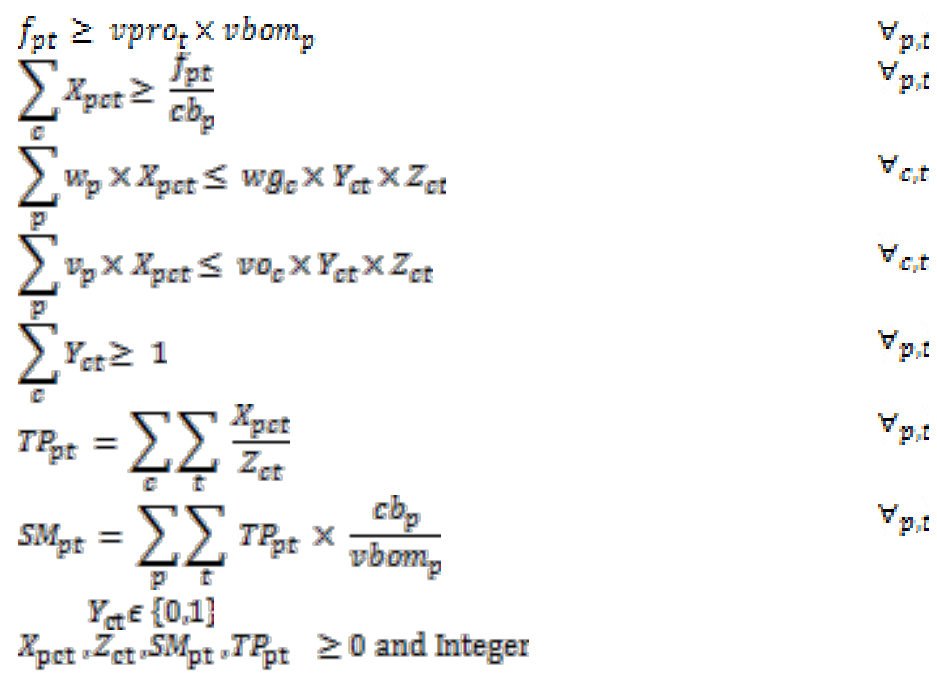

\section{Case Study of Automotive Industry}

This case study is based upon a real problem from the automotive industry. The manufacture has not implemented the optimal material delivery planning for the inbound logistics activities in the form of choosing the right container type and the quantity of containers used. However, it resulting in the large number of containers sent with low container utility because the quantity of the material transported inside the container has not been optimal. Hence, the large inbound logistics cost. Depending on the cost of inbound logistics, it may be beneficial to configure containers to maximize the container utilization. Out of the several containers available in the market today, the following container sizes are chosen for analysis that is 20 feet dry container, 40 Feet high cube container, 45 feet high cube container. The study conducted in one of the imported commodity parts from Brazil which consist of 14 parts required for producing bus vehicles and delivered only by sea freight in six periods.

\subsection{Type and Number of Container Used}

In logistics inbound activity, information about the type of container and the number of containers used is a very important decision to be determined, so the costs incurred as a result for delivery the materials can be optimal. The decision variable is influenced by the volume of production that produces the amount of material or box part that must be sent in each period. The amount of material delivered should also be adjusted to the capacity of each container type, where the inbound logistics cost that arise will be different for each type of container selected. 


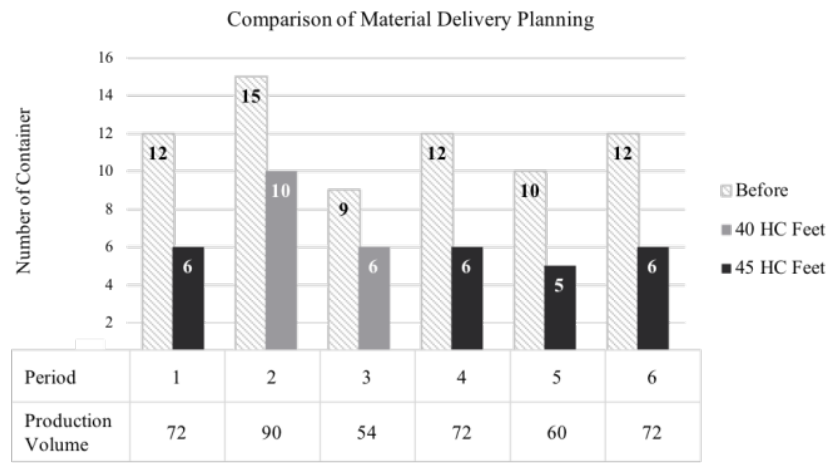

Fig. 2. Comparison of Material Delivery Planning

Due to the varying volume of production for each period, the type and quantity of containers used may change to achieve optimal cost. But unlike the material delivery before, where the delivery of material riveted only on one type of container that is $40 \mathrm{HC}$ Feet. Meanwhile, Figure 2 shows the number of containers delivered before the improvement is higher than the optimization model results. The situation is detrimental to the company because it causes the cost incurred is also greater, whereas the number of containers sent can still be reduced. Selection of this type of container will affect the number of sets parts carried in each container and also affect the inbound cost of logistics, especially transportation costs and port costs.

\subsection{Container Space Utilization Value}

The value of the container utilization is influenced by the selection of container types along with the container load. The decision variable for the amount of material load per container is affected by the capacity of each type of container used, where the difficulty in making this decision is that the number of box parts present in a container must produce a set of parts. Box part is some amount of part packed inside the box contains the minimum order quantity (lot size) which has been specified by the supplier while set part itself is the material needed to produce the component part for one unit of vehicle. Table 1 shows the type of container used and the amount of material load in the container. Thus, total count for the weight and volume of charges in each of the containers can be calculated.

Table 1. An Optimum Material Load Solution Output

\begin{tabular}{|c|c|c|c|c|c|}
\hline Period & $\begin{array}{c}\text { Container } \\
\text { Type }\end{array}$ & $\begin{array}{c}\text { Box part } \\
\left(\mathbf{T P}_{\mathbf{p t}}\right)\end{array}$ & $\begin{array}{c}\text { Set part } \\
\left(\mathbf{S M}_{\mathbf{p t}}\right)\end{array}$ & $\begin{array}{c}\text { Total weight } \\
(\mathbf{k g})\end{array}$ & $\begin{array}{c}\text { Total Volume } \\
\left(\mathbf{( m}^{\mathbf{3}} \mathbf{)}\right.\end{array}$ \\
\hline 1 & 45 HC Feet & 80 box & 12 & 25.897 & 80,82 \\
\hline 2 & 40 HC Feet & 60 box & 9 & 19.423 & 60,61 \\
\hline 3 & 40 HC Feet & 60 box & 9 & 19.423 & 60,61 \\
\hline 4 & 45 HC Feet & 80 box & 12 & 25.897 & 80,82 \\
\hline 5 & 45 HC Feet & 80 box & 12 & 25.897 & 80,82 \\
\hline 6 & 45 HC Feet & 80 box & 12 & 25.897 & 80,82 \\
\hline
\end{tabular}

Result of optimization model, indicate that the optimal load for container $45 \mathrm{HC}$ feet is 80 box part or 12 set part, while for container $40 \mathrm{HC}$ feet is 60 box part or 9 set part. From the data contained in Table 1, it can be calculated the value of container utilization for the indicator volume and weight that shown in Figure 3. 


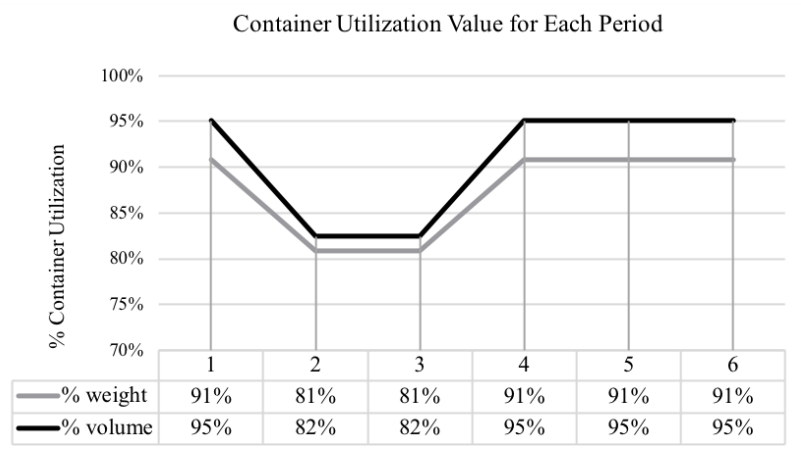

Fig. 3. Container Utilization Value Solutions Output

The number of material load per container from the optimization model resulted in higher container utilization values than the container utilization of previous material deliveries that only stood at $55 \%$ by only using container type $40 \mathrm{HC}$ Feet with material load in each container is 40 box part or 6 set part.

\subsection{Total Inbound Logistics Cost}

In this research optimization model, the objective function is to minimize the total cost of inbound logistics. The inbound cost of logistics calculated in the model, consisting of three commodities namely material cost, transportation costs, and all cost components arising from the activities at the port. The effort made to obtain minimal inbound logistics costs namely to reduce the amount of transportation costs and port charges. Meanwhile, for material costs incurred in pre-conditions and optimization model results in the same costs associated with the same amount of material delivery, so they are not taken into account.

Comparison of Inbound Logistic Cost

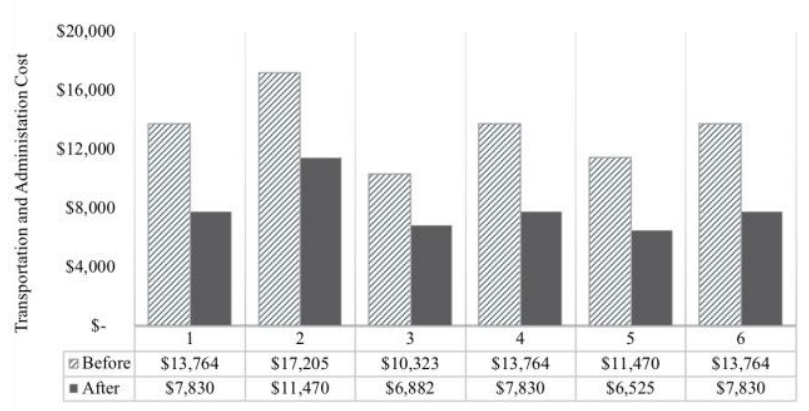

Fig. 4. Comparison of Inbound Logistics Cost

In Figure 4 can be seen transportation costs and port costs arising from the optimization model results less than the costs incurred in the conditions before due to the number of containers used is optimal because of the optimal load quantity inside container. Therefore, optimizing the selection of container types and the amount of material load may result in lower number of containers being used and a direct impact on the decrease of inbound logistics cost. Thus, the purpose of this research to minimize the cost of inbound logistics through the planning of delivery of part has been achieved. 


\section{Summary and Conclusions}

In this paper an optimization methodology, based on Mixed Integer Nonlinear Programming (MINLP) has been created to develop material delivery planning optimization model by determine the type and the number of container used as well as the total optimal material load in each container to reduce total cost of inbound logistics. A case study from the automotive industry is presented which demonstrates the capabilities of the optimization methodology. The results indicate the optimization lead to significant changes in total cost of inbound logistics, which reduce $40 \%$ of the transportation and administration cost. In addition, the solution output results an increasing of container utilization value for the material delivery. The scope of the model is limited to JIT supply chain systems, where supply is initiated only for the volume production. The load balance of containers and the arrangement of materials inside the container has not been explicitly considered in this research. During product transportation, damages may occur and so there may be damage costs. These costs have not been built into this model. These are all area of potential future work.

We would like to thanks PITTA Grant from Universitas Indonesia for funded this research.

\section{References}

1. J.L. Gattorna, D.W. Walters, Managing The Supply Chain ( Macmillan, London, 1996)

2. J.B. Holmstrom, P. Aavikko, J. Pro. Inv. Man. E 35, 1 (1994)

3. L. Harrington, J. Ship. Log. E 33, 155 (2008)

4. G.T. Crainic, G. Laporte, Eur. J. Op. Re. E 97, 409 (1997)

5. Y. Wu, and, K. K. Lai, Proceedings of the Sixth Biannual World Automation Congress, E 18, 329 (2004)

6. J. K. Cochran, and B. Ramanujam, Int. J. Prod. Eco. E 103, 826 (2006)

7. C. M. McDonald, Int. J. Prod. Eco. E 180, 208 (2016)

8. R.B. Michael, J.L. Larry, K. Yasanur, and A.G. Thomas, J. Bus. Log. E 33, 118 (2012) 